IRA-International Journal of Technology \& Engineering

ISSN 2455-4480; Vol.04, Issue 01 (2016)

Institute of Research Advances

http://research-advances.org/index.php/IRAJTE

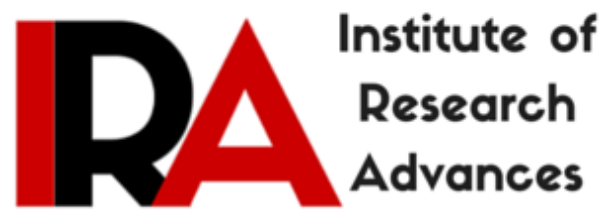

\title{
High Voltage Testing of Gas (SF6) Insulated Substation
}

\section{John De Britto C}

Assistant Professor, Department of EEE,

Parisutham Institute of technology and science,

Thanjavur-613 006,Tamilnadu,India.

DOI: http://dx.doi.org/10.21013/jte.v4.n1.p4

\section{How to cite this paper:}

C, J. (2016). High Voltage Testing of Gas (SF6) Insulated Substation. IRA-International Journal of Technology \& Engineering (ISSN 2455-4480), 4(1).

doi:http://dx.doi.org/10.21013/jte.v4.n1.p4

(C) Institute of Research Advances

\section{(cc) EY-NC}

This works is licensed under a Creative Commons Attribution-Non Commercial 4.0 International License subject to proper citation to the publication source of the work.

Disclaimer: The scholarly papers as reviewed and published by the Institute of Research Advances (IRA) are the views and opinions of their respective authors and are not the views or opinions of the IRA. The IRA disclaims of any harm or loss caused due to the published content to any party. 


\section{ABSTRACT}

A resonant test system with variable frequency has been used to perform the On-Site Testing. The paper mainly describes about the concept of High Voltage testing using resonant test system with variable frequency and the concept of high voltage fault sensing and tripping mechanism. A design of a $220 \mathrm{~V}$ switchgear arrangement is described and performance of high voltage testing is explained. A fault sensing circuit along the arrangement has also been briefed.

Keywords: GIS, $\mathrm{SF}_{6}, \mathrm{AC}$ testing, Power Frequency withstand test.

\section{INTRODUCTION}

GIS testing has been performed either by AC voltage, lightning impulse voltage or switching impulse voltage or a combination of them. A GIS AC-testing with an increased voltage level combined with sensitive partial discharge measurements met good the requirements for detecting the different fault causes. The AC test voltage for On-Site Testing can be generated by a series resonant test system with variable frequency (30 to $300 \mathrm{~Hz}$ ). The high voltage test kit itself contains the current sensing and the tripping circuit.

\section{GAS INSULATED SUBSTATION}

A gas insulated substation is an electrical substation in which the major structures contained in a sealed environment with the amount of sulfur hexafluoride gas as the insulating medium. A GIS, on the other hand,it requires very small space because of the excellent dielectric insulation properties of the medium.

The main applications for gas insulated substations in now a days are:

High voltage installations, these are usually $115 \mathrm{kV}$ and above but also down to $20 \mathrm{kV}$.

Urban installations, these are Installed in areas where the cost of real estate is significant.

Indoor installations, these are constructed within buildings whereas an AIS or other cannot other environmentally sensitive installations.

\section{SULPHUR HEXAFLUORIDE (SF6)}

\section{A. SF6 manufacture}

The synthesis of sulphur hexafluoride is by allowing fluorine obtained by electrolysis to react with sulphur according to the exothermic reaction: $\mathrm{S}+3 \mathrm{~F} 2 \rightarrow \mathrm{SF} 6+262 \mathrm{kcal}$

\section{B. Physical properties}

$\begin{array}{ll}\text { Density } & 6.14 \mathrm{kgm}^{-3} \\ \text { Thermal conductivity } & 0.0136 \mathrm{Wm}^{-1} \mathrm{~K}^{-1} \\ \text { Critical point: } & \\ \text { Temperature } & 45.55^{\circ} \mathrm{C} \\ \begin{array}{l}\text { Density } \\ \text { Pressure }\end{array} & 730 \mathrm{~kg} \mathrm{~m}^{-3} \\ & 3.78 \mathrm{MPa} \\ \text { Sound velocity } & 136 \mathrm{~ms}^{-1} \\ \text { Refractive index } & 1.000783 \\ \text { Formation heat } & -1221.66 \mathrm{kJmol}^{-1} \\ \text { Specific heat } & 96.6 \mathrm{~J} \mathrm{~mol}^{-1} \mathrm{~K}^{-1}\end{array}$

SF6 is one of the heaviest known gases, almost five times higher than that of air. The specific heat of SF6 is 3.7 times that of air.

This reduces the effects of heating within electrical equipment. The thermal conductivity of SF6 is below that of air.

\section{Chemical properties}

SF6 can be heated without decomposition to $500^{\circ} \mathrm{C}$ in the absence of catalytic metals. SF6 is generally non-flammable. Hydrogen, chlorine and oxygen have no action on it. SF6 is insoluble in water. It is not attacked by acids. Also in its pure state, SF6 has no toxicity.

\section{Electrical Properties}

The dielectric strength of SF6 is about 2.5 times, it is always higher than that of air. The excellent dielectric properties of SF6 are mainly due to the electronegative character of its molecule. It has a pronounced tendency to capture free electrons and heavy ions with low mobility making the development of electron avalanches very difficult.

C. Arc decomposition products

Generally an electric arc, the temperature can reach $15,000 \mathrm{~K}$ and a small proportion of SF6 is decomposed. Here the decomposition products are formed in the presence of: 1 . An electric arc formed 
by the opening of contacts normally comprising alloys are based on tungsten, copper and nickel, containing residual quantities of oxygen and hydrogen. 2. Impurities in the SF6 namely air, CF4 and water vapour. 3. Insulating components comprising plastic materials commonly based on carbon, hydrogen and silica, 4. Other metallic or nonmetallic materials from which the equipment is constructed.

\section{Other uses of SF6}

Electrical insulation in medical equipment (X-ray machines), or surgery, Electrical insulation in scientific equipments are electron microscopes, particle accelerators such as Van de Graf generators, Acoustic insulation in double glazed windows, and a tracer gas for studying airflow in ventilation systems, As a tracer for leak detection in pressurized system components, Inorder to give a special atmosphere for metallurgical processing (aluminium and magnesium) or for military purpose.

\section{AC or DC}

\section{A.Insulation Current Flow (AC)}

Insulation may be simply modeled as a capacitor in parallel with a resistor. The current flow that results will comprise two components: the capacitive current (Ic) and the resistive current (Ir).

$>$ For good insulation:

$>$ Ic $>=100 \times$ Ir

$>$ Ic leads Ir by close to $90^{\circ}$

For marginal insulation:

$>$ Ic $>=50 \times$ Ir

$>$ Ic leads Ir by $<=80^{\circ}$

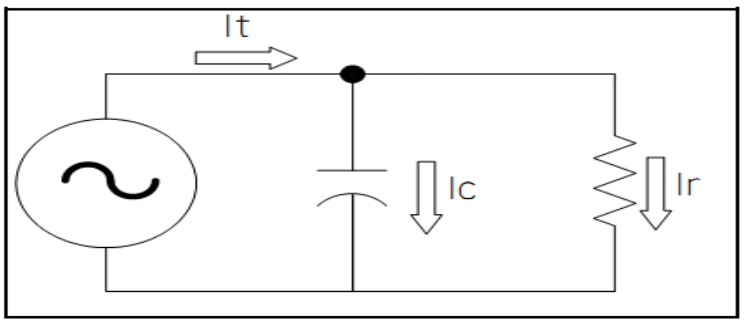

Fig. 1 Insulation with an AC voltage applied

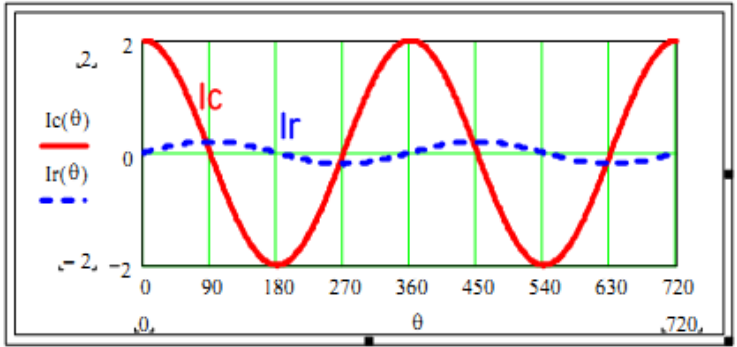

Fig.2 Insulation current with AC voltage applied

A. Insulation Current Flow (DC)

When switch S1 is closed, the DC supply is initially connected to the insulation system. In the DC model an extra capacitor has been added (dashed lines). The current that flows through this input capacitor is called the dielectric absorption current .

\section{B. Capacitive Current (Ic)}

The capacitive current is used to charge the capacitance in the system. It normally stops flowing a few seconds after the DC voltage is applied. Here the short burst of capacitive current flow may put a rather substantial stress on any test equipment that is mainly applied to very large insulation systems such as cables or large rotating machine.

\section{Dielectric Absorption Current}

The applied insulation voltage puts a stress on the molecules of the insulation. The positive side of the molecules is generally attracted to the negative conductor and the negative side of the molecules is attracted to the positive conductor of a circuit. And the resultant value is an energy that is supplied to the molecules much like force will realign a network branch of rubber bands. Like Ic, Ida usually off quickly as the molecules realign to their maximum extent.

\section{A. Resistive (Leakage) Current (Ir)}

This is the electron current flow that actually passes through the insulation. For an good insulation the resistive current flow will be relatively small and constant. In bad insulation the leakage current may be fairly large and it may actually increases the value with time. 


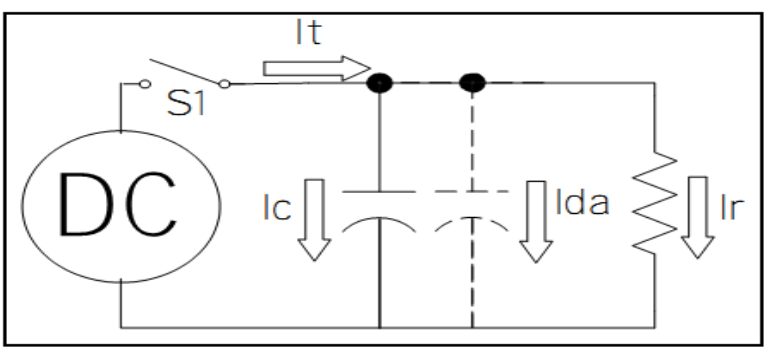

Fig.3 Insulation with DC voltage applied

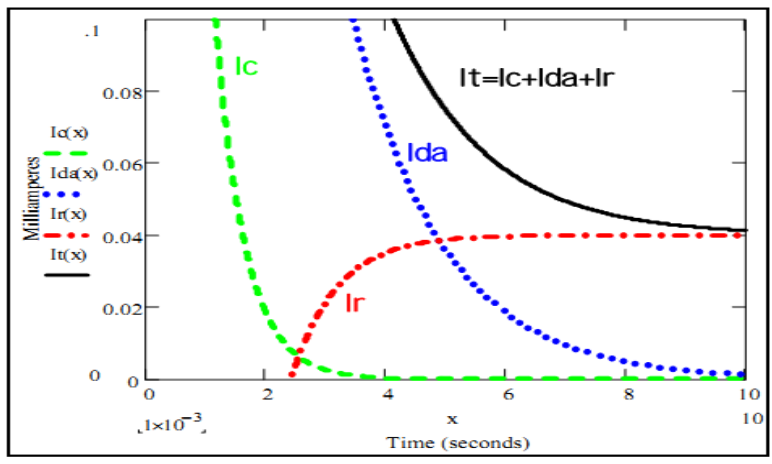

Fig.4 DC current flow in good insulation

\section{AC HIGH VOLTAGE TESTING}

In this test a high voltage $\mathrm{AC}$ is applied to the insulation. Usually, two or more times the rated insulation voltage will be used. The concept here is somewhat equivalent to overloading the dam with too much water. If the insulation is good, then it will not fail during the test. Note that failure during an AC high potential test is usually conducted very rapid and the insulation is completely destroyed. Because of this, the AC Over-potential test is classed as a gono go type of test.

A. Merits of AC High Voltage Testing

It can check both voltage polarities, whereas a dc test charges the insulation always in only one polarity.

This may become a concern for products that actually use ac voltage for their normal operation.

\section{A. Demerits of AC High Voltage Testing}

Since a large percentage of insulation current in both good and marginal insulation is capacitive in nature, good insulation will have close to the same amount of AC current flow as marginal insulation. It is now not possible to evaluate the quality of insulation by simply measuring the magnitude of current flow

The high amount of current flow drawn by the insulation requires a large test instrument to supply it. This causes AC test sets to be heavier and difficult to that transport than equivalent capability DC test sets.

\section{HIGH VOLTAGE TESTING EQUIPMENT}

On-Site Testing with conventional series resonant test systems of the insulating cylinder type RZ

The oil insulated series resonant reactors of the insulating cylinder type are designed for a longer test duty and higher power rating. Typical performance data of a two module tower is an output voltage up to $800 \mathrm{kV}$ and a $1 \mathrm{hp}$ output power of up to $3200 \mathrm{kVA}$ at a weight to power ratio of approximate. $5 \mathrm{~kg} / \mathrm{kVA}$. The test voltage is applied to the test object via an Air/SF6 bushing. Using with this design several modules can be cascaded to increase the test voltage but a complete encapsulated On-Site Test arrangement is not easy to achieve. Therefore the UHF PD measuring method is preferred when using this test arrangement. The auxiliary equipment such as exciter transformer, electrodes, base frames and the measuring capacitor is stored in a 20 inch container. Furthermore a control room is integrated in the container as well. The reactor itself is transported in a crate.

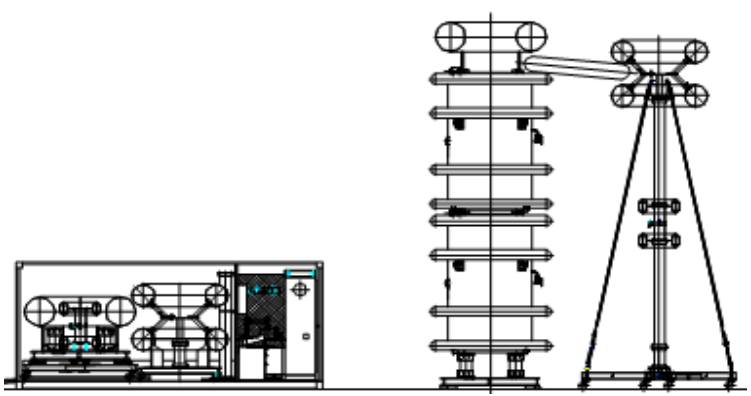

Fig.5 Conventional series resonant test systems of the insulating cylinder type RZ

\section{TESTING PROCEDURE FOR 220 KV GIS}

\section{A. Power Frequency withstand test:}

Test to be conducted as per IEC 62271-203 Table 102.

\section{B. Test Purpose}

The purpose is to ensure the dielectric strength on the main circuit. 


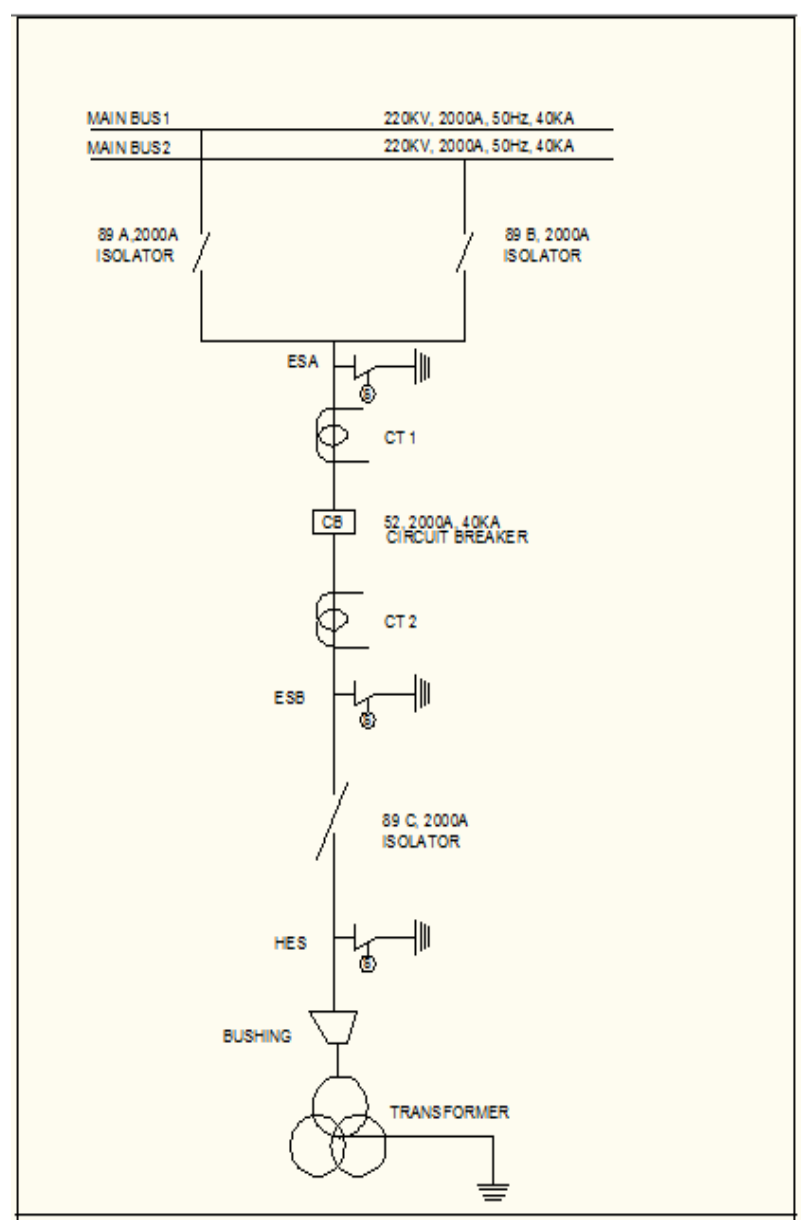

Fig.6 GIS Bay Arrangement

A. New switchgear

These test voltages shall apply to:

All extensible switchgear which incorporates site-made high-voltage connections.

Any non-extensible switchgear where work has been done affecting the insulation. For clarification, removal and replacement of the SF6 gas does not require dielectric retesting of the system.

Where factory assembled and tested GIS panels are supplied, comprising circuit-breaker, disconnectors and earth switches, dielectric testing of individual panels will not be repeated in this site but a test voltage of $5 \mathrm{kV}$ dc shall be applied for one minute.

\section{B. Existing switchgear}

These test voltages shall apply to:

$>$ All switchgear where work has been done affecting the insulation.

$>$ All switchgear which has been re- installed.

\section{A. Application of test voltage}

The test voltages shall be applied:

1. Between phases and phase to earth with the contacts closed.

Table 1. phase to earth

\begin{tabular}{|l|l|}
\hline Test voltage applied to & Earth applied to \\
\hline $\mathrm{L} 1$ & $\mathrm{~L} 3+\mathrm{L} 2$ \\
\hline $\mathrm{L} 2$ & $\mathrm{~L} 1+\mathrm{L} 3$ \\
\hline $\mathrm{L} 3$ & $\mathrm{~L} 1+\mathrm{L} 2$ \\
\hline \multicolumn{2}{|c|}{ OR } \\
\hline Test voltage applied to & Earth applied to \\
\hline $\mathrm{L} 1$ and L2 & $\mathrm{L} 3$ \\
\hline $\mathrm{L} 2$ and $\mathrm{L} 3$ & $\mathrm{~L} 1$ \\
\hline
\end{tabular}

2. Across the open contacts.(Unless assembled and dielectric tested in the factory).

Table 2. open contacts

\begin{tabular}{|l|l|}
\hline Test voltage applied to & Earth applied to \\
\hline $\mathrm{L} 1, \mathrm{~L} 2$ and $\mathrm{L} 3$ & $\mathrm{~L} 1, \mathrm{~L} 2$ and $\mathrm{L} 3$ opposite contacts \\
\hline
\end{tabular}

\section{B. Test Method}

The test shall be made after assembling test object completely, maintaining the minimum functional pressure and connecting CT all secondary terminals shorted. The test voltage shall be raised to the voltage through test bushing and maintained for 1 min.

\section{Acceptance Criteria}

Shall withstood \& No collapse of Voltage (No flashover).

\section{HIGH VOLTAGE TRIPPING MECHANISM}

The high voltage testing kit itself contains the tripping circuit along with the respective step up transformers for providing the high voltage along the gas insulated switchgear. It senses the current which ranges in mille amperes and when the leakage current along the line goes beyond a standard value as preset in the circuit, the trip circuit is activated and the GIS is tripped off from the testing kit thus preventing the damage along the switchgear insulation and also the equipment connected along it. 


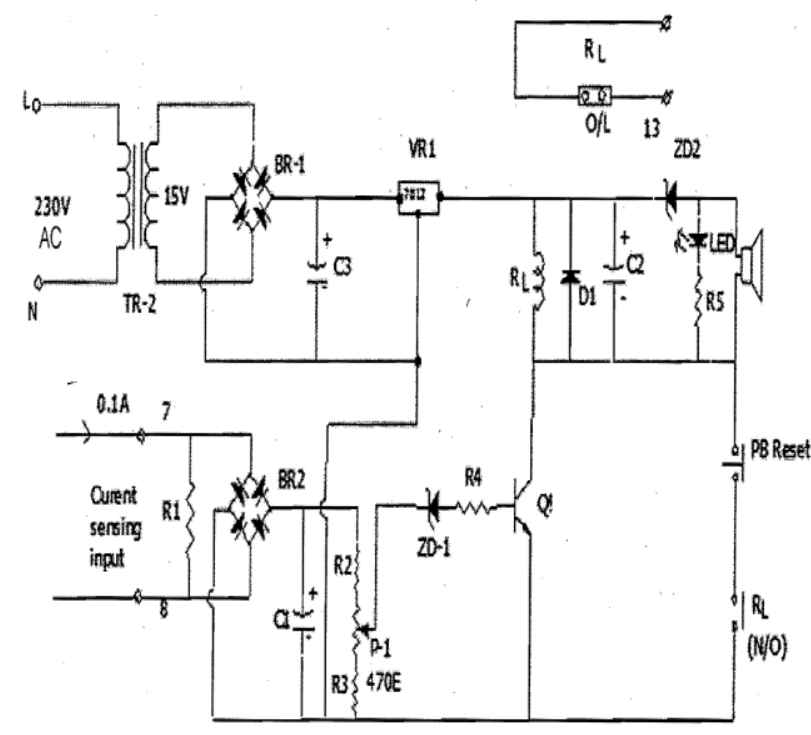

Fig.9 Tripping circuit for $220 K V$ switchgear

\section{TESTING IN $220 \mathrm{~V}$ SWITCHGEAR ARRANGEMENT}

Similar to the gas insulated switchgear, a mechanical arrangement is made such that the switchgear components are placed in their respective places as required for a $220 \mathrm{~V}$ bay structure. The mechanical arrangement consist of a bay feeding two buses Main Bus-A and Main Bus-B. The bay consists of three phases $\mathrm{R}, \mathrm{Y}$ and $\mathrm{B}$ and each phases has a line isolator, two current transformers, a circuit breaker and two bus isolator each connecting the two buses individually. But as these equipments are expensive and are quite larger in sizes, the components performing the same function of those equipments are implemented along their respective positions. And similarly, as $\mathrm{SF}_{6}$ gas is expensive and is available only for industrial usage, rubber insulation is provided along the switchgear. Aluminium string is used as conductor for performing the test. The power supply is made through a $415 \mathrm{~V}, 15 \mathrm{~A}$ auto transformer. As the phases are to be checked individually, a variable supply from 0 to $380 \mathrm{~V}$ is given to each phases individually. If the phases individually have withstood the high voltage of 380 $\mathrm{V}$ (as that to a $220 \mathrm{~V}$ line) succesfully without any damage to the insulation and have overcome without any natrual faults then the bay is said to have passed the test, if the GIS is Single Phase enclosure type. If the GIS is 3 phase enclosure type, then Phase to Phase testing also necessary.

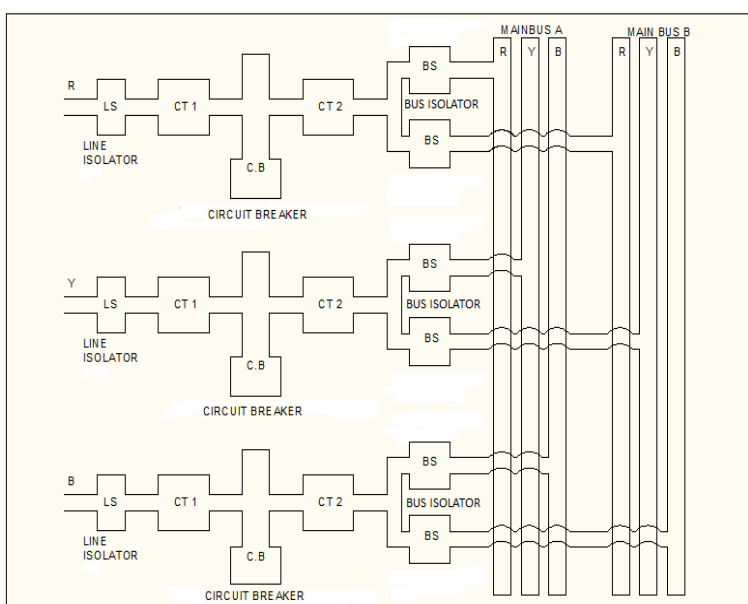

Fig.7 Mechanical structure of 220V switchgear arrangement

The supply is made by connecting two auto transformers in series such that their neutrals are connected to each other and the two phases are are led to a 2 way connector from which a single wire of phase voltage up to $400 \mathrm{~V}$ can be obtained by varying one by one.

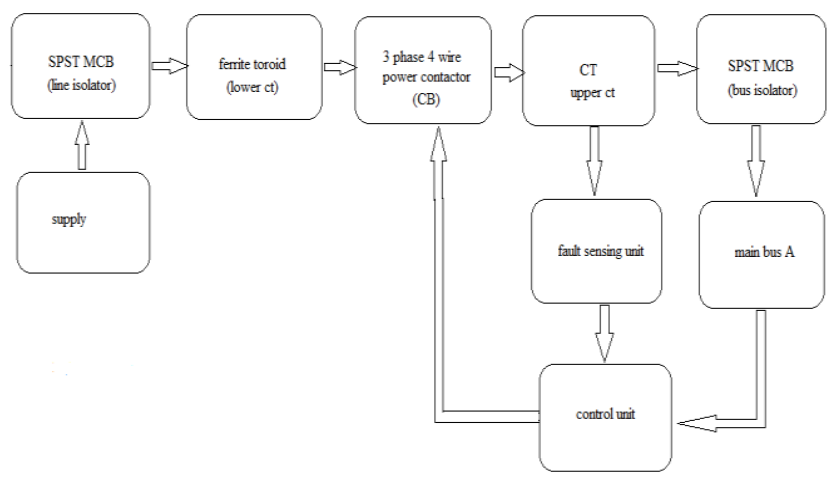

Fig.8 Block diagram of the 220V switchgear arrangement

\section{FAULT IDENTIFICATION AND TRIPPING MECHANISM IN $220 \mathrm{~V}$ ARRANGEMENTS}

To demonstrate the identification of fault along the switchgear, an earth fault is created manually through a Rheostat which leads to a short circuit along the bay. This would lead to flow of excessive current along the bay. Now, the control circuit connected along the power contactor senses the current which ranges in milli amperes and when the leakage current along the line goes beyond a standard value as preset in the circuit, the trip circuit is activated and the bay is tripped off from the supply thus preventing the damage along the switchgear 
insulation and also the equipments connected along it.

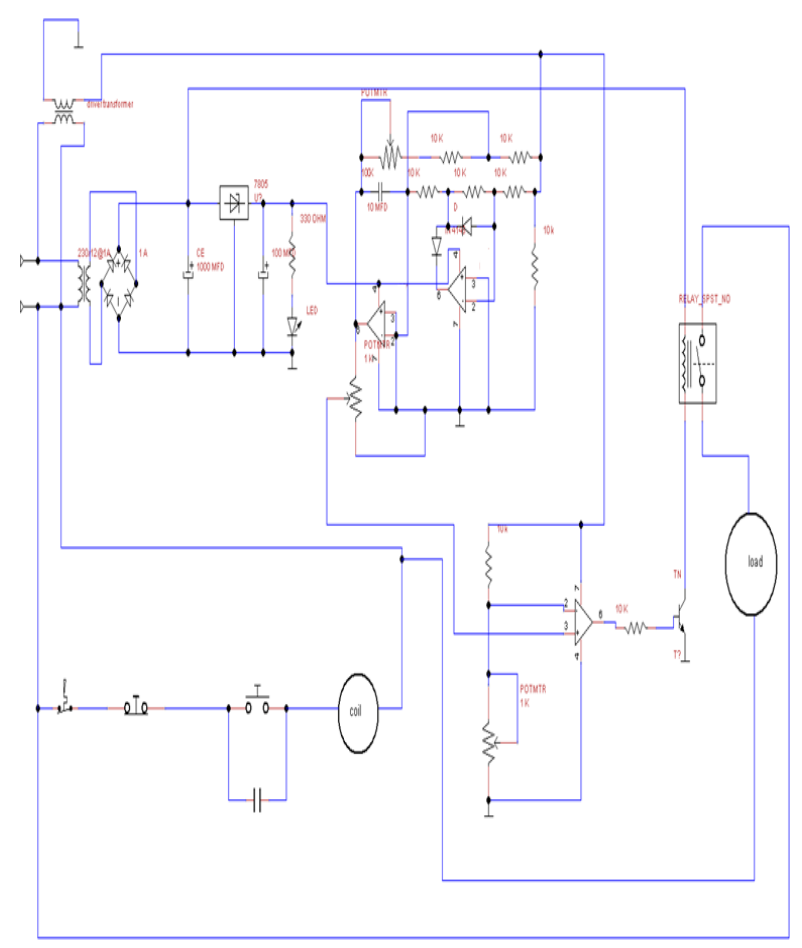

\section{CONCLUSION}

Thus a study on testing of gas insulated substation is made as per the power frequency withstand test. The testing kit used for power frequency withstand test contains the circuit for producing a high voltage and also the circuit for sensing the flow of leakage current along the insulation and tripping the main circuit thus preventing the damage of insulation and main circuit components. A design of $220 \mathrm{~V}$ switchgear arrangement has also been discussed along with the fault sensing circuit.

\section{REFERENCE}

[1] On-Site Testing of Gas Insulated Substation with AC Voltage by M. Gamlin, J. Rickmann, P. Schikarski, R. Feger, K. Feser. Haefely Trench Basel, Switzerland.

[2] Gas Insulated Substations by Dr. K. D. Srivastava. The University of British Columbia. December 2012.

[3] Cahier technique no. 188, SF6 properties, and use in MV and HV switchgear. D. Koch. Schneider Electric. February 2003.
[4] TECHNICAL BULLETIN - 012a, Principles of Insulation Testing. Cadic Corporation. January 9, 2002.

[5] Gubanski Stanislaw M. Wettability of Naturally Aged Silicone and EPDM Composite Insulators IEEE Transactions on Power Delivery, Vol. 5, No. 3, July 1990, pp. 1527-1535

[6] IEC 60099-4, Edition 1.2, 2001-12 Surge Arresters - Part 4: Metal-Oxide Surge Arresters Without Gaps for AC Systems.

[7] IEC 600143-2, Edition 1, 1994-07 Series Capacitors - Part 2: Protective equipment for series capacitor banks.

[8] IEEE Std. C62.11-1999 IEEE Standard for Metal-Oxide Surge Arresters for AC Power Circuits $(>1 \mathrm{kV})$.

[9] CIGRÉ Publication 33/14-05 Application guide for metal oxide arresters without gaps for HVDC converter stations.

[10] Diseko N.L. Performance of Metal Oxide Arresters in HVDC Stations CIGRÉ 1990 Session, 26th August - 1st September, paper 33-208.

[11] Horiuchi S. Power Dissipation Characteristics of Zinc Oxide Arresters for HVDC Systems IEEE Transactions on Power Delivery, Vol. 3, No. 4, October 1988 .

[12] Miroslaw Bartkowiak, Comber Michael G., Mahan Gerald D. Failure Modes and Energy Absorption Capability of $\mathrm{ZnO}$ Varistors IEEE Transactions on Power Delivery, Vol. 14, No.1, January 1999, pp. 152-162.

[13] Jean Mainville, Pierre Riffon, Louis P. Rollin, Volker Hinrichsen Pressure Relief Tests on Varistors for the Series Compensation Banks installed at the Montagnais Substation IEEE/PES 1993 Summer Meeting, Vancouver/Canada, paper 93, SM 385-5 PWRD.

[14] K. Steinfeld, V. Hinrichsen Field Experience with Online-Monitoring of Metal-Oxide Surge Arresters by Surface Acoustic Wave (SAW) Temperature Sensors 1 International Electrical Equipment Conference, 30-31 October 2001, Bilbao, Spain, paper 4.7 